\title{
DOST METAFORU İŞLETMELER İÇİN BİR ERDEM ARAYIŞI MI?: ELEŞTİREL BİR DEĞERLENDİRME
}

Emine ŞENER 1

ÖZ

Anahtar Kelimeler:

Dost Işsletme

Metafor

Örgütsel Metafor

Eleştirel Yönetim Çalışmaları

JEL Kodlarn:

M10,

M14,

M19
Received Date (Başvuru Tarihi): 14/04/2020

Accepted Date (Kabul Tarihi):

$23 / 05 / 2020$

Published Date (Yayın Tarihi):
$\mathrm{Bu}$ çalışmada; dost metaforu, işletme ölçeğinde sorunsallaştırllarak, ilgili metaforun neden/nasıl kullanıldı̆̆ ve sıklıkla karşılaşılan dost işletme kategorileri eleştirel teori bağlamında değerlendirilmiştir. Çalışmada öncelikle, eleştirel teori ve eleştirel yönetim çalışmaları açıklanmış, ardından işletme ve dost metaforu ilişkisi ortaya konulmaya çalışılmıştır. Örgütsel düzeyde metaforların eleştirel analizi, içinde yaşadı̆̆ımız dünyayı daha net algılayıp olumlu yönde geliştirilmesine katkı sağlayacaktır. Ana akım yönetim ve organizasyon çalışmalarının konfor alanının dışına çıkmaya cesaret eden ve mevcut teorilere şüpheyle yaklaşan eleştirel yönetim çalışmalarl, örgütleri sadece basit olarak bir takım mal ve hizmetleri sunan kuruluşlar olarak düşünmemekte, insan olmayl üreten ve yeniden üreten kuruluşlar olarak algllamaktadır. Çalışmada, dost metaforu işletme ölçeğinde, parçalı bir yaklaşımla, bütünsel olmaktan uzak, insanın farklı özelliklerini zayıflı derecesinde algılayan, gücün ve iktidarın sahibi olarak işletmelerin sözde hakikatçi bir tutumu olarak nitelendirilmektedir. Sonuç olarak; dost metaforu işletme ölçeğinde, kendini gerçekleştiren kehanet olma potansiyeli taşımaktadır. Eleştirel yönetim çalışmaları bağlamında, tüm kategoriler bir potada eritilirse, işletmelerin esas amaçlarına ulaşılacă̆ı düşünülmektedir.

Keywords

Friendly Business

M10
Methaphor

M14
Organizational Methaphor

Critical Management Studies

JEL Codes:

M19

\footnotetext{
${ }^{1}$ Dr. Öğr. Üyesi, Kırşehir Ahi Evran Üniversitesi, esener@ahievran.edu.tr, $\quad$ https:// orcid.org/0000-0002-8903-1684
} 


\section{EXTENDED ABSTRACT}

\section{IS FRIENDLY METAPHOR A QUEST FOR VIRTUE FOR THE BUSINESSES?: A CRITICAL REVIEW}

\section{LITERATURE SURVEY and RESEARCH SUBJECT}

The concept of human relations, which began to rise in the 1920s and 1930s, was based on the prison metaphor, although it placed the issue of how best to organize the work on an ideological framework. According to Fleming (2020), the employee has been treated tactfully and tolerantly since then within the conception of Taylorism, which is presented in a noble-hearted manner, until the moment he decides that he does not get what he has wanted. The main purpose here is to ensure the loyalty and commitment of the employee. Thus, the employee continues to work without feeling any discrepancy between himself and the business. The aim here is to make the employee work much more prolifically. In this context, the phenomenon of work and the relationship between the organization and employee has always been an issue to be carefully considered.

\subsection{RESEARCH PURPOSE and ITS IMPORTANCE}

In this study, friendly metaphor has been problematized on the scale of business, and why and how metaphor is used and why it has been described as false truthfulness in the study has been tried to be clarified through Foucault's "critical" approach, expressed in his words as "it is another dimension related to the importance of telling the truth, knowing who may tell the truth, and why we should tell the truth" (2019, s. 144). To this end, critical theory and critical management studies have been explicitly introduced in the first place, and then the relationship between business and friendly metaphor has been tried to be elucidated.

\subsection{CONTRIBUTION of the ARTICLE to the LITERATURE}

This study is seeking a critical answer to the question "Is friendly metaphor a search for virtue for businesses?" For this purpose, friendly metaphor was primarily attempted to be analyzed within philosophical contexts. Thus, as Bates $(2001$, p.582) stated, it was aimed to contribute to the effort to make the world we live in more transparent with a critical analysis through the metaphors that express our beliefs and actions. What's more, this study bears a critical aspect that will contribute to the structural transformation of businesses. Furthermore, since there is no study in the literature that discusses and examines the friendly metaphor issue outside the mainstream management approaches in the context of businesses, the door-opening feature of this study should not be overlooked.

\section{DESIGN and METHOD}

Critical management studies (Goldman, 2016) that dare to step out of the comfort area of traditional mainstream management and organization studies and thus approach the existing theories with suspicion (Goldman, 2016) aim at humanizing business processes, creating an alternative to bureaucratic structures, realizing democracy in the workplace, ensuring the participation of employees in management, and establishing a balance between work life and other areas of life. Organizations should not be considered simply as institutions that offer a number of goods and services. The basic principle that organizations are the establishments that produce and reproduce man (Cooper, 2001, Akt.:Ylldırım, 2010) is one of the main reasons why the use of friendly metaphor in organizations has been the main point of focus in this study.

\subsection{RESEARCH TYPE}

Although this study has the characteristics of a traditional review, the friendly metaphor concept used for businesses has been discussed from the perspective of critical management studies. 


\subsection{RESEARCH PROBLEMS}

This study is seeking a critical answer to the question "Is friendly metaphor a search for virtue for businesses?"

\section{FINDINGS and DISCUSSION}

Friendship, which is the subject of this study, is regarded as a virtue both in the works belonging to the Aristotle period and those after Aristotle. In studies conducted on the concept of virtue, we see friendship as a dimension in the scales developed to measure individual and organizational virtue. Businesses are rendered informal with the aforementioned friendly metaphor. This informalization blurs the boundary between work life and non-work life. This blurry condition basically plays a role in favor of the company, while it has the potential to turn into a rather disturbing picture for the employee. Metaphor, which is used to ensure high commitment to the business, also paves the way for the employee to encounter more workload.

Instead of "friendly metaphor," especially after 1990s, there is a use of "environmentally friendly enterprise" in businesses due to a sustainable environment concern. In addition, while there were a limited number of studies (Hogg \& Harker, 1992) on "family-friendly businesses" in the same period, the category of "user-friendly businesses" emerged with the inclusion of technology producing businesses. Today, it can be seen that friendly metaphor is widely used by businesses, but there is no critical and theoretical study on the subject.

According to the findings of this study, it is possible to say that new categories are added every passing day to the categories where friendly metaphor is being used, and even further, one may speak of fairly specific categories such as businesses that are food allergy friendly, train friendly, student friendly or user friendly. However, in this study, explanations particularly about women, family, baby and elderly friendly enterprises are included. Similar to employee-friendly businesses that have the capability to increase the employees' level of job satisfaction, strengthen their business relationships and ensure their participation in management, family and female-friendly businesses can also increase the productivity of their employees by reducing the time they spend in the business through part-time or flexible-time work programs. The friendly categories mentioned here naturally bring to minds Fleming's (2020) aphorism that "capitalism cannot exist without classes." However, it is not the laborcapital relations that are in question here, but it is the classes that capitalism creates to its favor. Gender, age and even religion are used in the society in a very functional way. As stated at the beginning, it is not possible to reach friendliness, which is a virtue, through false truthfulness. However, metaphors are elements with linguistic power that have the potential to transform organizational cultures in time. In this respect, it should be underlined that the use of friendly metaphor in organizations has eventually come to a point that cannot be underestimated.

\section{CONCLUSION and LIMITATIONS}

In this study, through a fragmented approach and with a style that is far from being holistic, it was tried to critically evaluate the issue of friendly metaphor used in the form of so-called truthfulness in organizations by possessing absolute power and command and perceiving various characteristics of employees in the form of weakness. The most important thing that the companies in different categories associated with friendly metaphor in the study should realize is that they could achieve their main goals only if all the aforesaid friendly categories are brought together within the organization. In short, it should be kept in mind that we cannot be innovation friendly without being employee friendly, and employee friendly or family friendly without being woman friendly. Friendly metaphor can be considered as an effort to close the flaws of enterprises with the help of a band-aid. Consequently, it would be beneficial to use the true friendly metaphor, which has the potential to be a self-fulfilling prophecy, rather than using it in the form of false truthfulness. At this point, does friendly metaphor have the potential to transform businesses? Or whether it will remain just a bandaid remains to be seen. Yet, what is known for now is that the enterprises are far from having conceived the understanding stated by Yunus Emre in his words: "Friend's house is our hearts, and I came to make hearts." 


\section{GİRIŞ}

"Dostluğu hem doğuran, hem sürdüren, erdemdir.

Erdem olmadan dostluğun hiçbir türü olamaz."

(Cicero)

1920'ler ve 1930'larda yükselemeye başlayan insan ilişkileri söylemi, çalışmanın en iyi nasıl örgütlenebileceğini ideolojik bir çerçeveye oturtmasına rağmen hapishane metaforuna dayaniyordu. Fleming (2020)'e göre o günden bugüne, alicenaplıkla sunulmuş Taylorizmde, çalışanın istediği şeylerin olmadığına karar vermesine dek düşünceli ve anlayışlı davranılır. Temel amaç, çalışanların sadakatini ve bağlılığını elde etmektedir. Böylece çalışan kendisi ve işletme arasında bir fark görmeden çalışmaya devam eder. Gaye ise çalışanın, daha fazla çalışmasını sağlamaktır.

Yukarıdaki giriş paragrafı, bir ölçüde Foucault'nun (2019) hakikati söyleme konusundaki dürüstlük olarak tanımladı̆̆ı, Antik Yunan'da "parrhesia" denilen hakikatçilik olarak nitelendirilebilir. Ancak çalışmada ele alınan, işletmeler için "dost metaforu" ise bu çalışmada, "sahte hakikatçilik" olarak nitelendirebileceğimiz bir paradigma üzerine inşa edilmiştir.

Çalışmada, dost metaforu işletme ölçeğinde sorunsallaştırılarak, metaforun neden ve nasıl kullanıldığı ve çalışmada neden sahte hakikatçilik olarak nitelendirildiği, büyük oranda Foucault'nun (2019, s. 144) “hakikati söylemenin önemiyle, kimin hakikati söyleyebileceğini bilmekle ve neden hakikati söylememiz gerektiğini bilmekle ilgili olan bir diğer boyut" olarak ifade ettiği "eleştirel" yaklaşımla gerçekleştirilmeye çalışılmıştır. Bu amaçla, önce eleştirel teori ve eleştirel yönetim çalışmaları açıklanmış, ardından işletme ve dost metaforu ilişkisi ortaya konulmaya çalışılmıştır. Böylece, Bates'inde (2001, s.582) belirttiği gibi inançlarımızı ve eylemlerimizi ifade eden metaforların, eleştirel analizi ile içinde yaşadığımız dünyayı daha şeffaf hale getirme çabasına katkı sağlanmak amaçlanmıştır. 


\section{ELEŞTİREL TEORİ VE ELEŞTİREL YÖNETİM ÇALIŞMALARI}

1920'lerden itibaren sosyal sorunlar üzerine çalışan Frankfurt Üniversitesi Sosyal Araştırmalar Enstitüsü, süreç içerisinde Frankfurt Okulu'na dönüşmüştür. Adorno ve Horkheimer ile başlayan süreç, Habermas ile sürmüştür. Bu süreçte, Marksist paradigmadan uzaklaşan Frankurt Okulu'nun ürünü, sosyoloji ve felsefe ekolünün paradigması olan eleştirel teori, pozitivist bilim üretme sürecini sorgulamaya dayalı post-pozitvist bir yaklaşımdır. Kızılçelik'in (2008, s. 440) deyişiyle:

“Eleştirel teori, egemen felsefi ve sosyolojik söylemlerin dışında kalmış, pozitivist felsefe ve sosyoloji evine dâhil olmamış, onların avlusunda durmuş, kutsal kazanlarına kendini atmamış buna karşın farklı sosyal bilim disiplinlerine ve felsefeye kapısını sonuna kadar aralamış edebiyat, sanat, estetik, müzik, ekonomi, siyaset ve tarihle komşuluk ilişkilerini zinde tutmuş, disiplinler arası bir felsefi sosyoloji çizgisidir."

Kısaca eleştirel teori, felsefe ve sosyal bilimleri sentezleme girşimidir. Bu yönüyle de entelektüellerin sıklıkla başvurduğu ve kabuk tutmuş sorunları, dokunulmadık, arka sokaklarda yaşananları açı̆̆a çıkarma potansiyeli de taşımaktadır. Çünkü eleştirel teori, hayatın bir kritiğidir.

Eleştirel teori yaklaşımı, "sosyal olayların görüldü̈̆ü ve gösterildiği gibi anlaşılması yerine muhalif, şüpheci bir analiz biçimi öneren bilimsel bir yaklaşımdır." (Willmott, 2005, Aktaran: Keskin vd., 2016). Eleştirel teorinin önde gelen isimlerinden Horkheimer'e göre araştırmacı, sınıf temelli, metalaşmış ve programlanmış topluma muhalif olmayı seçmelidir (Morrow, 1994, Akataran:Yıldırım, 2010). Temelde pozitivizm eleştrisi olan yaklaşımın, "Bilgi objektif değildir, doğa bilimlerinde olduğu gibi evrensel kurallara tabi olamaz. Bilgi, değer yargılarından bağımsız değildir, toplumsal tarih ve kültürel gelişimle bağlantılıdır ve mevcut toplumsal düzenin olduğu gibi kabul edilmemesi gerekir." olmak üzere üç temel iddiası vardır (Keskin vd., 2016). Eleştirel teori, hâkim ideolojilerin etkisi altında bilimsel bilginin geliştirilmesinin karşındadır. Çünkü hâkim ideoloji, taraflı ve yanıltıcı sübjektifliklere gebedir bu nedenle çoğunlukla, güçlü tarafın sorunlarını ve ilgilerini dile getirir.

Yönetim ve organizasyon çalışmalarında eleştirel teori, yönetimin tarafsız ve erdemli olması adına sorunsallaştırmalar peşinde olan eleştirel yönetim çalışmaları 
yaklaşımı olarak karşımıza çıkmaktadır. 1990'ların ortalarında İngiltere merkezli olarak belirmeye başlayan ve eleştirel teorinin, yönetim çalışmalarında kullanımı ilkesini benimseyen Eleştirel Yönetim Çalışmaları (Critical Management Studies), dili sadece temsil eden değil aynı zamanda oluşturan bir olgu olarak görür. Bu nedenle örgütsel düzeyde kullanılan sembol ve kavramların gerisindeki gerçekleri ortaya çıkarmayı hedefler.

Eleştirel yönetim çalışmaları (EYÇ), yönetim uygulamasını kökten dönüştürmek amacıyla ana akım yönetim teorisine bir dizi alternatif sunmaktadır. Odak noktası, hâkim yönetim ve örgütlenme biçimlerinin ahlaki savunulabilirliği ile sosyal ve ekolojik sürdürülebilirliği konusunda derin şüpheciliktir. EYÇ’yi harekete geçiren, ne yöneticilerin kişisel başarısızlıkları ne de belirli kuruluşların kötü yönetimidir, esas olan bu yöneticilerin ve kuruluşların hizmet verdiği, yeniden ürettiği daha geniş sosyo-ekonomik sistemlerin, sosyal adaletsizliği ve çevresel yıkıcılığıdır (Adler, Forbes ve Willmott, 2007). Geleneksel, ana akım yönetim ve organizasyon çalışmalarının konfor alanının dışına çıkmaya cesaret eden ve mevcut teorilere şüpheyle yaklaşan eletirel yönetim çalışmaları (Goldman, 2016) iş süreçlerini insanileştirme, bürokratik yapılara alternatif yaratma, iş yerinde demokrasiyi gerçekleştirme, yönetime çalışanların katılımını sağlama ve çalışma hayatı ile hayatın diğer alanları arasında denge kurma amaçları taşımaktadır. Örgütler sadece basit olarak bir takım mal ve hizmetleri sunan kuruluşlar olarak düşünülmemelidir. Onlar insan olmayı üreten ve yeniden üreten kuruluşlardır (Cooper, 2001, Akt.: Yıldırım, 2010) temel anlayışı, bu çalışmanın esas gerekçelerinden biridir.

\section{3. İŞLETMELER VE DOST METAFORU}

Başlangıcından bu yana, kapitalizm ister normdan ayrılma, isterse özünü oluşturma olsun sayısız etik dışı davranışla ilişkilendirilmiştir (Prasad ve Mills, 2010). Ancak “20. yüzyılda yaşadı̆̆ımız biçimiyle endüstriyel kapitalizmden hızla uzaklaşıyoruz ve tekrar geçmişe dönme ihtimalimiz çok az." (Frase, 2018). Bu yüzden mevcut sistem dâhilinde en iyiyi aramaya devam edeceğiz. "İstihdam ilişkisi, pür bir iktisadi işlem olarak görülseydi, neye benzerdi bir düşünün." diyor Budd (2018), 
hakaniyet, söz hakkı ve verimlilik üçgeninde çalışma ilişkilerini tartıştı̆̆ "İnsani Çalışma İlişkisi" adlı kitabında. Budd'un (2018) sorusunu düşünürek başlanılan bu çalışma istihdam ilişkisinin organik yönüne, erdeme doğru yol alacağımız etik bir nitelik taşımaktadır. Çünkü etik düşünce, birlikte yaşam kültürüyle ilgili olup uyum ve denge arayışıdır. Çalışmada da erdem etiği baz alınarak, işletmeler açısından bir değerlendirme yapılmıştır. Erdem etiği işletmeleri, sorumluluğu olan ve bünyesindeki bireyleri birbirine rakip olarak etkileşim halindeki unsurlar olarak gören, sosyal uzlaşmayı geliştiren, işbirlikçi, adaletli, dürüst ve dost olarak görür (Budd, 2018).

$\mathrm{Bu}$ amaçla, eleştirel teorinin ayırt edici özelliği olan şeyleşme ve yabancılaşmayı reddediş ve özgürleşme bağlamında değerlendirme yapılmaya çalışılmıştır. Ayrıca tüm bu değerlendirmelerin tarihsel bağlamdan bağımsız olamayacağını da belirtmekte fayda vardır.

Birinci sanayi devriminin diğer bir ifadeyle endüstri $1.0^{\prime}$ ın sembolü niteleiğindeki Cromford Mill Fabrikası (Resim 1-2), aynı zamanda dünyanın su ile çalışan ilk pamuk ipliği fabrikasıdır. Richard Arkwright tarafından 1771 yılında inşa edilen fabrika binası, iş ilişkileri bağlamında önemli bir göstergedir. Su kaynağına yakın ama yaşam alanlarına uzak bir bölgede kurulan bu fabrika kullandığı yeni teknoloji ile geçim kaynaklarının tehlike altında olduğunu düşünen Ludditelerin (makine kırıcılar) saldırılarından korunmak amacıyla yüksek duvarlarla çevrilmiştir (Mcauley, Duberley ve Johson, 2019).
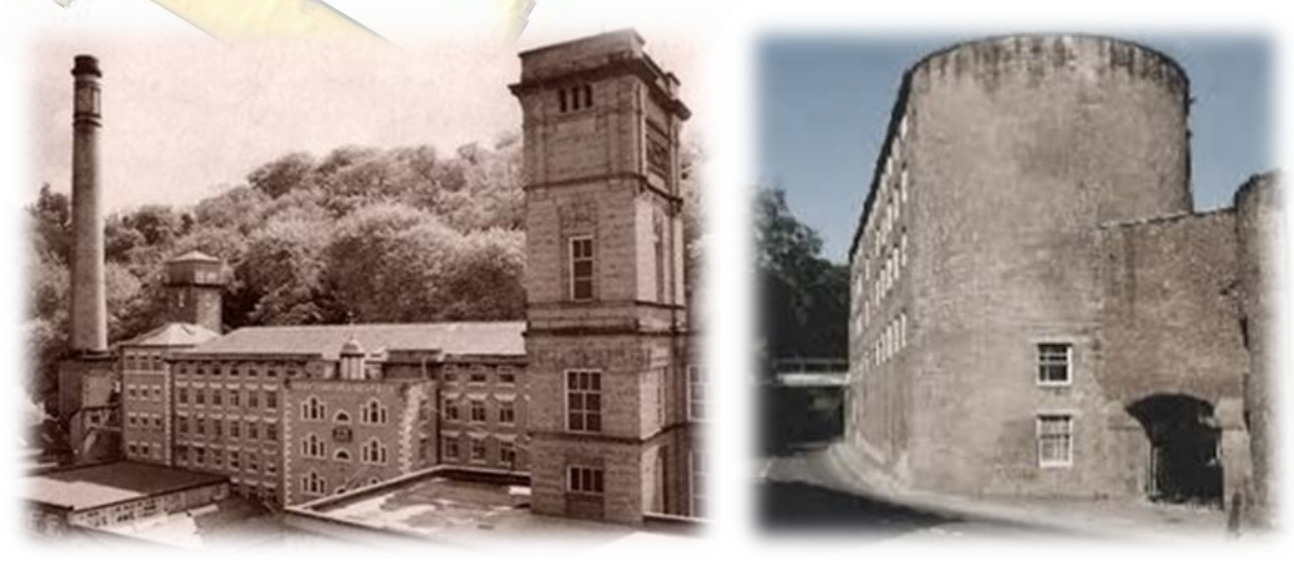

Resim 1-2. Cromford Mill, 1771

(Cromford Mill, 2020a; Cromford Mill, 2020b) 
Modern teknolojinin bazı yönlerine direnen insan ve örgütleri tanımlamak için kullanılan Ludditlere ilişkin Jongerden (2010, s. 191): “Ortak inancın tersine Ludditler teknolojinin kendisine karşı olmayıp, teknolojinin toplumsal egemenlik aracı olarak kullanılmasını, teknolojinin değerden muaf ve otonom olduğu iddiasın reddetmektedirler." demektedir. 1640-1660 yılları arasında başlayan hareket, toplumsal reform ve işçi sendikaları ile siyasete girip yasal örgütlere dönüşmüş ve 19. yüzyılın bitiminde sona ermiştir (Jongerden, 2010). Teknolojinin çalışanların iş ve çalışma hakları/koşullarını etkilemesini olumlu bir perspektifden değerlendirmek de gerekmektedir. Endüstri $1.0^{\prime}$ dan 4.0'a geldiğimiz günümüz koşullarında, teknolojiyi çalışanların iş çevresini, performansını geliştirecek şekilde kullanmak mümkündür. Resim 3-4'te Cromford Mill'den yaklaşık 250 yıl sonra Londra'da oldukça şık ve geniş bir çalışma alanı içinde spor salonu, masaj salonu ve dans stüdyosu da olan bir alan olarak tasarlanmış Google Şirketinin Londra Merkez Binası, işletmeler için dost metaforunun kullanımının oldukça boş ve popülize edilmiş bir söylem niteliği taşıdığını kanıtlar niteliktedir. Çünkü değişen sosyal, ekonomik, kültürel, teknolojik koşullar işletmlerin de çalışan lehine dönüşmesi gerektirdiğini göstermektedir. Google çalışanlarının şirketlerine ilişkin olumlu açıklamaları oldukça dikkat çekicidir (Youtube.com, 2020). Çünkü üzerinde düşünülmesi gereken ya da diğer ifadeyle göz ard1 edilen bir nokta endüstri ilişkileridir. Elbette dost kavramı, sadece iş gören lehine kullanılan bir kavram değildir, aynı zamanda müşteriye yönelik bir takım hizmetlerin özelleştirilmesini nitelemek amacıyla da kullanılmaktadır. Ancak özellikle işgören noktasında Budd'un (2017) söz hakkı, verimlilik ve hakkaniyet üçgeninde açıklamaya çalıştığı yeni endüstri ilişkileri bağlamında yaklaşmak dost metaforuna ilişkin çalışmanın başında sunulun hipotezi güçlendirmektedir. 2015 yılında Google, çalışanlarına destekleyici ve tatmin edici bir çalışma ortamı sunma konusundaki kararlılı̆̆ nedeniyle "Fortune Dergisi" ve "Great Place to Work Enstitüsü" tarafından 2007 y1lından itibaren çalıştığı sektörün en iyi şirketi seçilmiştir. Google'ın çalışan dostu işyeri uygulamalarının, çeşitli yenilikçi ve başarılı projelerin kuluçka merkezi olmak için çok önemli olduğu düşünülmektedir. Eşzamanlı olarak Google, inovasyonuyla da dikkat çekmektedir (Chen, Leung ve 
Evans, 2016). İlerleyen kısımda da belirtileceği üzere işletmelerin başarısı ancak bütünsel bir çaba ile mümkün olabilmektedir.
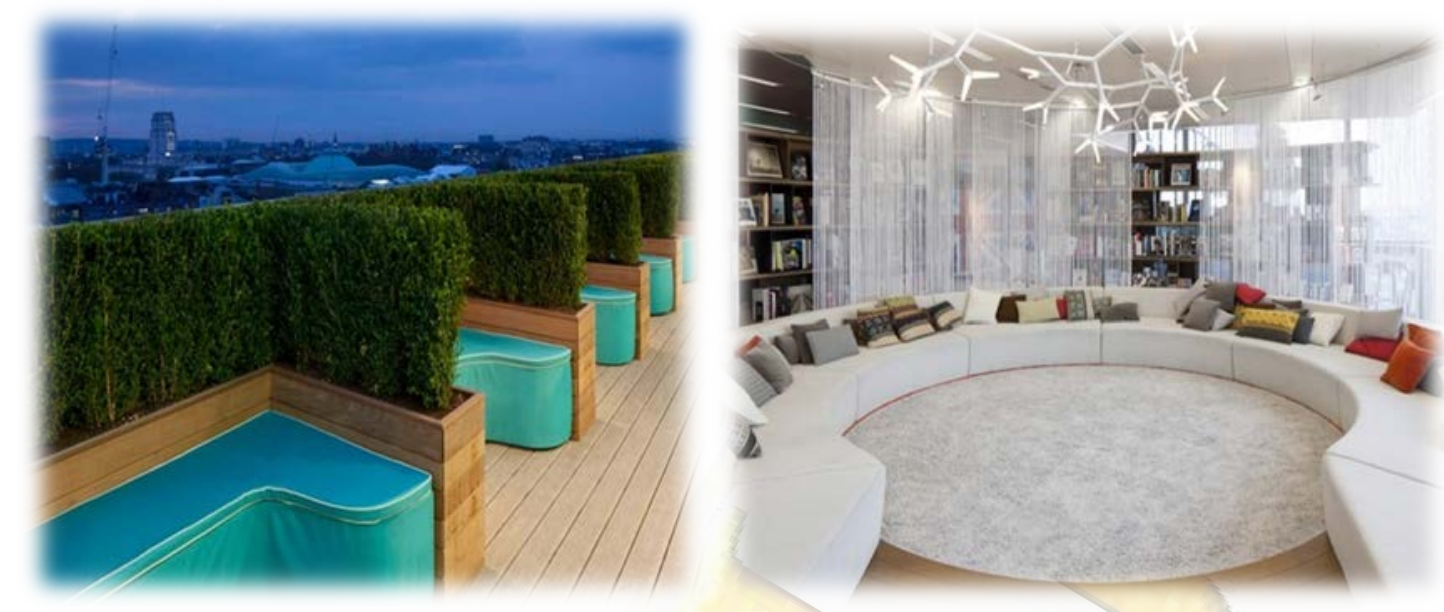

Resim 3-4. Google Şirketinin Londra Merkez Binası, 2020

(Google Londro Mekez Binası, 2020)

$\mathrm{Bu}$ çalışma, dost metaforu işletmeler için bir erdem arayışı mı? sorusuna eleştirel olarak yanıt aramaktadır. Bu amaçla aşağıda, öncelikli olarak dost metaforu felsefi okumalar eşliğinde analiz edilmeye çalışılmıştır.

\subsection{Dost Metaforu Üzerine}

"Dostlarm bulunduğu yerde adalete gerek yoktur. Ama adillerin adalete ek olarak dostluğa ihtiyact vardır. Ve adil olan da en adil olan dostlar arasında olandır."

(Aristoteles, 2009: 155)

Dili ve onu kullanma şekli, sahip olunan paradigma ile yakından ilişkilidir. İnsan düşünebildiği, üretebildiği ölçüde dilini kullanabilir ve dönüştürebilir. Sadece bilimsel paradigmalarda değil, örgütsel paradigmalar da dil, retorik ve örgütsel uygulamalardan etkilenir. Bu noktada metaforlar, örgütleri ve örgütsel paradigma değişimlerini sakince anlatmakta önemli bir işleve sahiptir. Tarihsel süreçte, örgüt teorilerinin gelişimi incelendiğinde, farklı metaforların dönemin özelliklerini kısa ve hızlıca anlatabildiği görülür. "Makine", "hapishane”, "sanal” gibi metaforlar ilk akla gelenlerdendir. Bunun yanı sıra Adam Smith'in piyasaya ilişkin kullandığı "görünmez el" metaforu hâlâ sıklıkla başvurulan metaforlardan biridir. Kendi içinde bir dönüşümünde habercisi olma potansiyeli taşıyan metaforlar bu yönüyle değişim 
ajanı da sayılabilir. Bu tablo, bu çalışmada kendini gerçekleştiren kehanet şeklinde ifade edilmiştir. Bates (2001), Nietzsche'nin (1968), “metaforlar entelektüel süreçlerin temelini oluşturur ve biz onları gerçeği ve anlamı inşa etmek için kullanırız. Metafor oluşturmaya dönük yönelim, kategorileştirme, sınıflandırma ve ilişki kurma süreçleriyle ilişkili olup gücü elde etme ile de özdeşleşmektedir. Metaforlar, yaşamı inşa etmemizi ve ona anlam katmamızı sağlar." dediğini belirtmektedir. Bates (2001, s. 579) aynı zamanda, metaforların örgüt kültürünü ifade eden araçlar olduğunu vurgulamaktadır.

Çalışmanın konusu olan dostluk, gerek Aristo gerekse Aristo sonrası çalışmalarda bir erdem olarak nitelendirilmektedir. Erdem üzerine yapılan çalışmalarda bireysel ve örgütsel erdemin ölçülmesi amacıyla geliştirilen ölçeklerde dostluğu bir boyut olarak görmekteyiz (Racelis, 2013; Cameron vd., 2004). Aristo (2010, s. 208) dostluk ile ilgili şöyle demektedir:

“Dostluk duygusu yürekten yani, ruhlarımızdaki sevme gücünden doğar. Bunu şuradan anlıyoruz ki sevdiğimiz kişilerin bizi ihmal etmesi, duygularımızı, tanımadı̆̆ımız kimselerin davranışlarından daha çok sarsar." İnsanlar kendilerine iyilikle davranılmasının hakları olduğunu sandıkları zaman, bundan yoksun bırakılınca ve umdukları yararı elden kaçırınca kırgınlık duyarlar (Aristo, 2010). Nikomakhos'a Etik adlı eserinde, sekizinci kitapta, Aristo (2009) dostluğu bir erdem olarak nitelendirirken, “erdemle birlikte giden şey" olarak da ifade etmektedir. Dostluk ve yardım, fikir birliği ilişkisine değinen Aristo dostluğu, hoş ve yararlı olarak nitelendirmekte hazza bağlı olan dostluğun uzun sürmeyeceğini söylemektedir. Ayrıca, benzerlerin dostluğunun mükemmel olacağını belirtmektedir. "Birlikte tuz tüketmeden birbirini tanımak olanaksızdı" diyerek birlikte zaman geçirip, paylaşımda bulunmayı da gerekli görmektedir. Aristo'nun dostluk üzerine olan sekizinci kitabında yer alan kavramlar Şekil 1'de verilmiştir. 


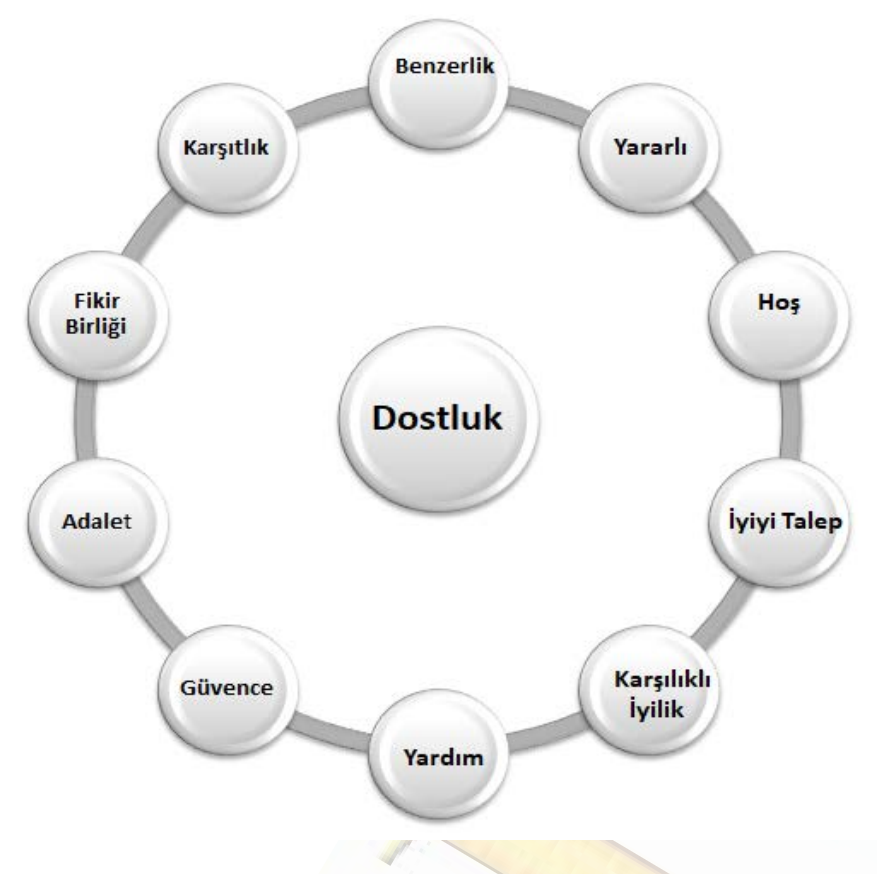

Şekil 1. Aristo'ya Göre Dostluk ve Etrafındaki Kavramlar Kaynak: Yazar tarafından üretilmiştir.

Şekil 1'de görüldüğü gibi ilgili metinde, dostluk kavramı tanımlanırken etrafında yer alan diğer önemli kavramlar araştırmacı tarafından, benzerlik, yararlı, hoş, iyiyi talep, karşılıklı iyilik, yardım, güvence, adalet, fikir birliği, karşıtlık olarak belirlenmiştir. Cicero (2007) ise "dostluğu hem doğuran, hem sürdüren, erdemdir; erdem olmadan dostluğun hiçbir türü olamaz" demekte ve "Dostluk, birçok iyiliği bir araya toplar, gözlerini nereye çevirirsen onu orada hazır bulursun, hiçbir yere yabancl, hiçbir zaman yersiz ve can sıkıcı değildir." diyerek övmektedir.

Cicero (2007), dostluk hep yardıma ihtiyaç duyulduğunda ya da zayıf olunduğu zamanlarda değil, her zaman talep edilmediğinde de desteğe hazır olmakla ilgilidir demektedir. Ayrıca, dostların ahlakı tertemiz olmalı; aralarında her konuda, düşünüşlerinde, isteklerinde, ayrımsız, tam bir anlaşma olmalıdır. O'na göre dostlukta aranılan süreklilik ve kararlılığın temeli, bağlılıktır. Bağlılık olmadan hiçbir şey sürekli olamamaktadır.

MacIntyre, günümüzde dostluk kavramının siyasi ve toplumsal içeriğinin ortadan kalkıp, sadece kişiler arasında duygusal bir durumdan ibaret bir konuma yerleştiğini söylese de son zamanlarda artık işletmeler de bu kavramı bir can simidi 
olarak kullanmaya başlamıştır (Kaptan, 2014; Şener, 2018). Örgütsel imaj ve itibar yönetiminde önemli bir yer tutmaya başlayan bu metafor, o kadar ileri gitmiştir ki başlangıçta çevre dostu, aile dostu, çalışan dostu, diye başlayan işletmeler bugün işi iyice abartarak, kültürel çeşitlilik dostu, kadın dostu, bebek dostu, çocuk dostu, yaşlı dostu, kullanicı dostu, hayvan dostu, bisiklet dostu, tren kullanan dostu ve hatta besin alerjisi dostu şeklinde yelpazeyi genişletmiştir.

\subsection{Dostluk, Sosyal Sorumluluktan Daha Fazlası}

"Uydurma şeyler çabucak kendi doğalarnna geri döner. Temelinde doğruluk yatan her şey zeminden boy atar, zaman geldiğinde de daha büyük daha iyi olarak ortaya çıkar (Seneca, 2015)".

Kurumsal sosyal sorumluluk ve kurumsal vatandaşlik alanına dâhil edilen bazı faaliyetler örgütsel erdemliliği temsil edebilirken, bu faaliyetler genellikle enstrümantal fayda veya değişim ilişkileri tarafından motive edildiği açıklanmaktadır. Yani, bu eylemlere katılım sıklıkla işletmeye fayda sağlamak için veya karşılıklılık anlaşması sonucunda başlatılır. Örneğin; kurumsal bir itibar elde etmek için (Cameron, 2003).

"İşletmelerin başlıca amacı kâr elde etmek değil ortak değer yaratmaktır. Bu noktada ortak değerin nasıl yaratılacağını öğrenmek ve işletmeyi yeniden meşrulaştırma yolunda bir adımdır" görüşündeki Porter ve Kramer (2011), işletme düşüncesindeki bir sonraki büyük dönüşümün ortak değer yaratma düşüncesiyle doğacağına inanmaktadır. Ancak onların bu iyimser tavrını Fleming (2020), kapitalizmin kurtarılma çabası olarak nitelendirmektedir. Hatta biraz daha ileri giderek kurumsal sosyal sorumluluğu bir ideoloji olarak ele alıp "herkesin kazandığı” bir senaryo sunan yaklaşımını "tıraş" diye nitelendirmekte, aile dostu kapitalizmi bir mit olarak değerlendirmekte ve kurumsal sosyal sorumluluğa ilişkin aşağıdaki ifadeleri kullanmaktadir:

“Kurumsal sosyal sorumluluk dişardaki diğer kesimler (hükümet yetkilileri, sivil toplum örgütleri, protesto grupları vb.) kadar, potansiyel ve mevcut işgüçlerini hedeflemek için de sık sık kullanılmıştır. Bu bir yana, büyük şirketlerin toplum için "iyi işler yapma" maskesi kapitalizmin erdemlerine en yürekten inanlar açısından bile pek inandırıcı değildir, sıklıkla da komiktir. Bu nedenle, kurumsal sosyal sorumluluk genel olarak "yeşilci göz boyama", "propaganda" ve "saçmalık" diye değerlendirilip 
kenara birakılır."

İşletmeler sözü edilen dost metaforuyla gayrı resmîleştirilmektedir. Bu gayrıresmileştirme ise iş hayatı ile iş dışı hayat arasındaki sınırı bulanıklaştırmaktadır. Elbette ki bu bulanıklaştırma temelde işletme lehine bir rol üstlenirken iş gören için oldukça rahatsız edici bir tabloya da dönüşme potansiyeli taşımaktadır. Yüksek bağlılık sağlama amacıyla kullanılan metafor, iş görenin daha fazla iş yükü ile karşılaşmasına da zemin hazırlamaktadır.

Diğer taraftan oldukça kişiselleştirilmiş olan uygulamalar ile elde edilmek istenen ilk elden iş göreni etkileyip, daha istekli hale getirmenin ötesinde gücün sahibini sürekli hatırlatmak olduğu da söylenebilir. Böylece işletme kendi iktidar anını uzatmak adına aslında dost metaforu arkasına sığınmaktadır. Diğer taraftan Fleming (2020) günümüz işletmelerinin bu tür uygulamlarla aslında rıza üretmeye çalışarak işgörenin içine sokulduğu bu duruma karşı sevgi duymasının sağlandığını belirtmektedir. Biraz daha ileri giderek kişinin kendini gerçekleştirme isteğinde işletmenin işbirliği yaparak kişinin arzusuna cevap veren bir nesne haline gelip işgöreni özne k1lma gayesidir.

Çalışanın ihtiyaçlarının olduğunu ve bunların giderilmesi gerektiği hakikatini dile getirenin işletmeler olması, Foucault'nun (2019) parrhasie olgusu ile çelişmektedir. Çünkü ona göre hakikatin söylenmesinin bir takım koşulları vardır. Parrhesia kullanan kişi, parrhesiastes, aklındaki her şeyi boşboğazlık etmeden söyleyen kişidir. Hakikati herhangi bir dolaylama, retorik kullanmadan doğrudan söyler. Bu doğrudan söyleme elbette bir takım riskleri de barındırmaktadır. Ancak hakikati söyleyen bu riskleri kabul eder ve içerdiği riskten sonra kaybetmeyi de göze alır. Bu kaybetme ihtimali etkinliğin daha çok aşağıdan yukarı doğru olmasına neden olur. Yani bir kral ya da tiranı parrhesia yaparken göremezsiniz çünkü kaybetme riskini almak istemezler. Parrhasie, hakikati ispat etmeyi değil, eleştirmeyi gerektirir ve parrhesia kullanan kişi, eleştirdiği kişiden genelde güçsüzdür, bu nedenle daha çok aşağıdan yukarıya doğrudur. Bir çocuğun babasını, bir öğrencinin öğretmenini, bir işgörenin patronunu eleştirmesi parrhesiadır. Fakat burada esas nokta, hakikat, bir ödev anlayışıyla ifade edilmeye çalışılır ve ahlaki yönü vardır. Ancak dost 
metaforunu kullanan işletmeler bu hakikati yukarıda sayılan ölçekte kullanmamaktadir.

İşletmelerde dost metaforunun, özellikle 1990'lardan sonra sürdürülebilir bir çevre kaygısıyla "çevre dostu işletme" şeklinde kullanımına rastlanmaktadır. Bunun yanı sıra aynı dönemde sınırlı sayıda "aile dostu işletme" çalışması (Hogg ve Harker, 1992) var iken, teknoloji üreten işletmelerin sürece dâhil olması ile "kullanıcı dostu işletme" kategorisi karşımıza çıkmaktadır. Günümüze geldiğimizde, işletmeler tarafından yaygın biçimde dost metaforunun kullanıldığı ancak konu üzerine eleştirel boyutta kuramsal bir çalışma yapılmadığı görülmektedir. Aşağıda Tablo 1'de sıklıkla kullanılan dost işletme kategorileri verilmiştir.

Tablo 1. Sıklıkla Kullanılan Dost İşletme Kategorileri ve Özellikleri

\begin{tabular}{|c|c|}
\hline & Dost İşletme Kategorileri \\
\hline Çalışan Dostu İşletme & (Gray, 2002) \\
\hline Kadın Dostu İşletme & $\begin{array}{c}\text { (Bangladesh Women Chamber of Commerce, 2020; Sparc } \\
\text { Advocacy Trainings, 2020; Emerging Lessons on Women's } \\
\text { Entrepreneurship, 2020; Capital Dergisi Kadin Dostu } \\
\text { Şirketler, 2020) }\end{array}$ \\
\hline Aile Dostu İşletme & (Gray, 2002) \\
\hline Çevre Dostu İşletme & (Majurin, 2017) \\
\hline Bebek Dostu Hastane ${ }^{2}$ & (Sevim ve Şener, 2019) \\
\hline Bakım ve Hasta Dostu Hastane ${ }^{3}$ & (Güven, 2007) \\
\hline Çocuk Dostu İşletme & (Children are Everyone's Business, 2020) \\
\hline Yaşlı Dostu İşletme & (Age-Friendly Business, 2020) \\
\hline Hayvan Dostu İşletme & (Berkey, 2020) \\
\hline Bisiklet Dostu İşletme & (Bicycle Friendly Business, 2020) \\
\hline Gizlilik Dostu İşletmeler & (Liu, Bonazzi, Fritscher ve Pigneur, 2011) \\
\hline İnovasyon Dostu İşletme & (Chen, Leung ve Evans, 2016) \\
\hline
\end{tabular}

Tablo 1'de verilen kategorilere her geçen gün yenisinin eklendiğini, hatta bunlara ek olarak, besin alerjisi dostu, tren kullanan dostu, öğrenci dostu, kullanıcı dostu işletme gibi oldukça spesifik kategorilerinde mevcut olduğunu söylemek mümkündür. Ancak burada özellikle kadın, aile, bebek ve yaşlı dostu işletmeler üzerinden açıklamalar yapılacaktır. Çalışanların, iş doyumunu artırma, ilişkilerini güçlendirme ve yönetime katılımını sağlama özelliğine sahip çalışan dostu işletmeler gibi aile ve kadın dostu işletmeler de yarı zamanlı ya da esnek çalışma ile çalışanların

2,3 Hastaneler için kullanılmaktadır. Ancak özellikle sağlığı bir hak olarak gören sağlık politikası benimseyen ülkelerde böylesi metaforların kullanılması oldukça düşündürücüdür. Sağlık bir bütündür ve verilen hizmetler bu şekilde kategorize edilemez. Tüm hastanelerin hasta dostu olması beklenilendir. Ya da yeni doğan bebeğe ve annesine tüm hastanelerde aynı yaklaşımla hizmet sunulması temel insan hakkıdır. 
işletmede geçirecekleri süreleri azaltan uygulamalardır. Ancak uzun vadede işletme yöneticileri bağlılıkta ve iş deneyiminde azalma (Gray, 2002; Lewis, 1997) raporladıkları için çoğu işletme bu riski göze almak istememektedir. Bunun yanı sıra inovasyon dostu işletmeler ile çalışan dostu işletmeler arasında ilişki olmasının tesadüf olmadığı açıktır. Çünkü yetenekli çalışanları çekecek, kariyer olanakları sağlayacak ve elde tutacak uygulamalar ile ancak inovasyon gerçekleştirilebilir. Literatürde, çalışma yeri kalitesi ile patent sayısı arasında da yüksek korelasyon olduğu belirtilmektedir (Chen, Leung ve Evans, 2016).

İşletmedeki toplam çalışan içerisinde kadın çalışan oranını, kadınlar lehine artırma çabasındaki işletmeler kadın dostu olarak anılmaktadır. Kadınların hem iş hem de ev sorumluluklarının göz önünde bulundurulmadan işletmelerin bu metaforu kullanması oksimorondan öteye geçmemektedir. Gelişmekte olan sosyoekonomik çevrelerde (özellikle Bangledeş, Nijerya gibi güney Asya ülkeleri) (Bangladesh Women Chamber of Commerce, 2020; Sparc Advocacy Trainings, 2020; Emerging Lessons on Women's Entrepreneurship, 2020) oldukça dikkat çekici şekilde kullanılan kadın dostu metaforu, olması gerekeni gerçekleştirme adına bir araç niteliği taşımakta, ekstra bir rol üstlen(e)memektedir. Örneğin 2013 yılından beri Türkiye'de kadın dostu işletme ödülleri adı altında 8 ayrı kategori yer almakta (Capital Dergisi Kadın Dostu Şirketler, 2020) ancak bu kategoriler çalışan ve yönetici oranlarından/sayılardan farklı bir içerik barındırmamaktadır. Yukarıda dost kavramı ve etrafındaki kavramların verildiği Aristo'dan mülhem şekil, dikkate alındığında, ilgili tablonun dost kavramının içeriğinde yer alan birçok unsurdan yoksun olduğu görülebilmektedir. Öyle ki kadın dostu olmak için ve bir erdem olarak dostluk inşa edebilmek için Farabi' nin erdem tanımındaki, "en yüksek iyi” ye ulaşmak gereklidir. Oraya da ancak bilgi ile varılacağı aşikârdır. Yani kadın dostu olmanın yolu bir varlık olarak kadını, iş hayatında baş etmek zorunda olduğu sorunlarla baş başa bırakmamaktır. Anneliği ve kadın olmasından dolayı sahip olduğu fizyolojik özellikleri bir sorun olarak sahaya süren işletmeler, çalıştırdıkları kadın sayılarıyla dost olma potansiyeli taşımamaktadır. Aile dostu olarak nitelendirilen birkaç göstermelik uygulama, bireylerin ve özellikle kadınların işyaşam dengesini kurmaları için yeterli olmamaktadır. Örgütler, çalışanların bağlılık 
ve azimle uzun saatler boyunca çalışmalarını, iş yerinde sürekli hazır bulunmalarını veya sık sık seyahat etmelerini beklemek yerine, onların iş ve özel yaşamda ayrı ayrı sorumlulukları olduğunu kabul etmek zorundadırlar (Mainiero ve Sullivan, 2005).

Hastane kavramının geliştirilmesi ve dönüştürülmesi ile ortaya çıan kavramlardan biri olan Bebek Dostu Hastane, uzun vadede hastane kavramının içinde yer alacak herhangi bir unsur olarak düşünülmektedir. Süreç içinde, parçalı (anne dostu, bebek dostu, bakım dostu) yaklaşımlardan sağlığın ve insan haklarının bütünselliği adına vazgeçileceği öngörülmektedir. Dost metaforunun hastanelerin güçlü yönlerine atıfta bulunan bir kavram olup olmadığı ise tartışılmalıdır (Sevim ve Şener, 2019). Bir diğer dost işletme olan yaşlı dostu işletmelerin, sahip olduğu özelliklerin neler olacağına ilişkin geliştirilen kontrol listelerinde (Age-Friendly Business, 2020); ("Tabelada büyük, okunması kolay ve kontrast yazılar kullanır (örn. Siyah beyaz arka plan üzerinde harfler)", "Merdivenlerde sağlam korkuluklar vardır.", "Döşeme kaymazdır.", "Döşeme parlak değildir.", "Paspaslar zemine sabitlenmiştir.", "Tekerlekli sandalye erişim yollar iyi işaretlenmiştir.") burada oldukça fazla yer kaplayacak ancak diğer dost işletmelerde de dikkati çeken, insanın insan olmasından dolayı sahip olduğu haklar bağlamında, var olması gereken özellikler sıralanmaktadır. Çevre dostu, yeşil işletmeler ise çevreye zarar vermeyen, temiz teknolojiler kullanan işletmeler olarak tanımlanmakta ve sürdürülebilirlikteki fonksiyonları önemle vurgulanmaktadır. Ancak olması gereken bir özelliğin olağan dışı olarak sunulması oldukça dikkat çekicidir.

Yukarıda verilen kategoriler dikkate alındığında, Fleming'in (2020) "kapitalizm sınıfsız var olamaz" deyişini akla gelmektedir. Ancak burada sözü edilen emek-sermaye ilişkisi değil kapitalizmin kendi lehine oluşturduğu sınıflar kastedilmektedir. Toplumsal cinsiyet, yaş hatta din oldukça işlevsel bir şekilde kullanılmaktadır. Başta da belirtildiği gibi, sahte hakikatçilik ile bir erdem olan dostluğa ulaşmak mümkün değildir. Ancak metaforlar süreç içerisinde örgüt kültürlerini dönüştürme potansiyeli olan dilsel güç öğeleridir. Bu yönüyle dost metaforunun kullanımını, işletmelerin geldiği noktada küçümsenmeyecek bir nokta olduğunu söylemek gerekir. 


\section{SONUÇ VE ÖNERİLER}

Bu çalışmada, parçalı bir yaklaşımla, bütünsel olmaktan uzak, insanın farklı özelliklerini zayıflık derecesinde algılayıp gücün ve iktidarın sahibi olarak sözde hakikatçilikle kullanılan dost metaforu eleştirel olarak değerlendirilmeye çalışılmıştır. Tablo 1'de de verilen dost metaforuyla anılan, farklı kategorilerdeki işletmelerin fark etmesi gereken en önemli husus verilen tüm dost kategoriler, ancak bir araya getirilirse işletmelerin esas amaçlarına ulaşılacağıdır. Kısaca, çalışan dostu olmadan inovasyon dostu; kadın dostu olmadan çalışan dostu ve aile dostu olunamayacağı unutulmamalıdır. Dost metaforu işletmelerin açılarını yara bandı marifetiyle kapatma çabası olarak değerlendirilebilir. İşletmeler uzun vadede, bütünsel, gerçekçi ve erdemli bir yaklaşımla işletme kitaplarında yer alan temel amaçlarına ulaşabileceklerini göz ardı etmemelidirler. Ancak Bauman (2010) her ne kadar:

“...ayakta kalma oyununda, güven, şeref ve merhamet, intiharla eş anlamlıdır. Eğer bütün herkesten daha çetin ve daha az dürüst değilsen, seni katlederler, belki içleri acıyarak belki de hiç vicdan azabı duymadan. İşte Darwin'in dünyasına geri döndük her durumda ayakta kalan en iyi şekilde uyum sağlayandır ya da daha ziyade diğerlerinden daha uzun süre ayakta kalmak uyum sağlamış olmanin en temel kanitıdır."

dese de erdem, topluluklarda iyi vatandaşlığın ayrılmaz bir unsuru, etkileşim refahı ve toplumsal istikrar için alan yaratmaktadır. Bu nedenle toplumun hayatta kalmasını sağlamak için şarttır. Erdemli bir örgüt için gerekli olan ilk şey, içerdiği kendine has uygulama-kurum kombinasyonu için iyi bir niyettir. İkinci olarak barındırdığı uygulamanın devamlılığını sağlamak ve bunun üzerine kurulduğundan haberdar olmalıdır. Ve mutlaka uygulamadaki mükemmelliği aramaya devam etmelidir (Tsoukas ve Chia, 2013). Dost metaforu bu bağlamda, sadece mükemmellik arayışında bir adım olarak olumlanabilir. $\mathrm{Bu}$ bakış açısıyla, işletmelerin standartlaşmış ve bütünsel fayda sağlamalarına katkı sağlamak amacıyla akreditasyon ve sertifikasyon benzeri zorunlu uluslararası uygulamalar geliştirilebilir. Tedarikçi, hizmet sağlayıcılar ve tüm paydaşların kalite standartlarında olduğu gibi bu tür uygulamaları da talep etmesinin yasal zeminde oluşturulması, metaforun hakikate dönüşmesine ve kendini gerçekleştirmesine katkı 
sağlayacaktır. Bundan sonra yapılacak olan, kendini dost olarak nitelendiren işletmeleri (kadın dostu, çocuk dostu, bebek dostu, hasta dostu, yaşlı dostu $v b$ ) içeren karma desenli, işgören-işveren perspektifinden olguyu derinlemesine incelemeye dönük çalışmaların da kehanetin gerçeğe dönüşmesinde payı olacaktır.

Sonuç olarak; kendini gerçekleştiren kehanet olma potansiyeli taşıyan dost metaforunu, sahte hakikatçilik olarak kullanmaktan vazgeçip, belki de elden bırakmamakta fayda vardır. Bu noktada, dost metaforu işletmelerin dönüşmesini sağlar $m \imath$ ? Yoksa sadece bir yara bandı mı? bekleyip görmek gerekecektir. Ancak bilinen o ki, işletmelerin, Yunus Emre'nin “Dostun evi gönüllerdir, gönüller yapmaya geldim” diyen dizelerine şimdilik oldukça uzakta olduğudur. 


\section{KAYNAKLAR}

Adler, P.S., Forbes, L.C., ve Willmott, H.C. (2007). Critical Management Studies. The Academy of Management Annals, 1(1), 119-179.

Age-Friendly Business. (2020). Erişim Adresi: https://www.calgary.ca/CSPS/CNS/Documents/

Aristo. (2009). Nikomakhos'Etik. (S. Babür, Çev.) Ankara: BilgeSu Yayıncılık.

Aristo. (2010). Politika. İstanbul: Remzi Kitabevi.

Bates, R.J. (2001). Eleştirel Teori Açısından Eğitim Yönetimi (Çev.: Selahattin Turan, Mehmet Şişman). Kuram ve Uygulamada Eğitim Yönetimi, 28, 573-592.

Bauman, Z. (2010). Etiğin Tüketiciler Dünyasında Bir Şansı Var mı? . Ankara: De ki yayım.

Bangladesh Women Chamber of Commerce \& Industry (2020). Erişim Adresi:

https://www.cleancookingalliance.org/partners/item/999/2147

Berkey, B. (2020). Prospects for an Animal-Friendly Business Ethics. Forthcoming in Animals and Business Ethics.

Bicycle Friendly Business District Implementation Manual. (2020). Erişim Adresi: https://media.metro.net/bikes/images/BFBD_Implementation_Manual_2019-04-02.pdf

Budd, J. W. (2018). İnsani Bir Çalışma İlişkisi Verimlilik Hakkaniyet ve Söz Hakkını Dengelemek. İstanbul: Küre Yayınları.

Capital Dergisi Kadın Dostu Şirketler (2020). Erişim Adresi: https://www.pwc.com.tr/kadin-dostu$\underline{\text { sirketler-2019 }}$

Cameron, K. (2003). Organizational Virtuousness and Performance, (Chapter 4 in Cameron, K.S., Dutton, J.E., ve Quinn, R.E. (2003) Positive Organizational Scholarship. San Francisco: Berrett-Koehler. Cameron, K., ve Caza, D. (2004). Exploring The Relationships Between Organizational Virtuousness And Performance. American Behavioral Scientist, 47, 766-790.

Children are Everyone's Business. (2020). Erişim Adresi: https://www.unicef.org/csr/css/

Cromford Mill. (2020a). Erişim Adresi: https://www.sutori.com/story/

Cromford Mill. (2020b). Erişim Adresi: http://www.thepeakdistrict.info/derbyshire-towns-villages/

Chen, J., Leung, W.S., ve Evans, K.P. (2016). Are employee-friendly workplaces conducive to innovation? Journal of Corporate Finance, 40, 61-79.

Cicero. (2007). Dostluk Üzerine. Homer Kitabevi.

Emerging Lessons on Women's Entrepreneurship in Asia and the Pacific. (2020).

Erişim Adresi: https://seepnetwork.org/files/galleries/

Fleming, P. (2020). Çalışmanın Mitolojisi Kapitalizm Kendine Rağmen Nasıl Ayakta Kalıyor? İstabul: Koç Üniversitesi Yayınları.

Foucault, M. (2019). Doğruyu Söylemek. İstanbul: Ayrıntı Yayınları.

Frase, P. (2018). Dört Gelecek: Kapitalizmden Sonra Dört Hayat. İstanbul: Koç Üniversitesi Yayınları. 
Goldman, G. A. (2016). On the possibility of fostering critical management studies in South Africa. (G. Goldman içinde, Critical Management Studies in the South African context, ss. 3-29) Cape Town: AOSIS.

Google Londro Mekez Binası. (2020). Erişim Adresi: https://www.icmimaritasarim.com.tr/londra-dagoogle-sirketinin-merkez-binasi.html

Gray, H. (2002). Family-Friendly Working: What a Performance! An Analysis of the Relationship Betweenthe Availability of Family-Friendly Policiesand Establishment Performance. London: Centre for Economic Performance London School of Economics and Political Science.

Güven, H. (2007). Bakım Dostu Hastaneler'in Standartlarının Belirlenmesi. İstanbul: Haliç Üniversitesi, Yüksek Lisans Tezi.

Hogg, C., ve Harker, L. (1992). The family-friendly employer: examples from Europe. New York: Daycare Trust in association with Families and Work Institute.

Jongerden, J. (2010). Ludditler ya da Teknolojide Siyaset- Bir Giriş (Teknoloji ve Toplum içinde, Ed. Guido Ruivenkamp, Joost Jongerden, Murat Öztürk). İstanbul: Kalkedon Yayıncılık.

Kaptan, F. E. (2014). Erdem Merkezli Bir Adalet Teorisi. ÏÜHFM, LXXII(1), 759-804.

Keskin, H., Akgün, A. E., ve Koçoğlu, İ. (2016). Örgüt Teorisi. Ankara: Nobel Akademik Yayıncılık.

Kızılçelik, S. (2008). Frankfurt Okulu. Ankara: Anı Yayıncılık.

Lewis, S. (1997). Family Friendly Employment and Policies: a Route to Changing Organizational Culture or Playing About at the Margins? Gender, Work and Organization, 4(1), 13-23.

Liu, Z., Bonazzi, R., Fritscher, B., ve Pigneur, Y. (2011). Privacy-Friendly Business Models for LocationBased Mobile Services. Journal of Theoretical and Applied Electronic Commerce Research, 6(2), 90107.

Mainiero, L. A., ve Sullivan, S. E. (2005). Kaleidoscope careers: An alternate explanation for the "optout" revolution. Academy of Management Executive, 19(1), 106-123.

Majurin, E. (2017). Green Business Booklet. Geneva: International Labour Organization.

Mcauley, J., Duberley, J., ve Johson, P. (2019). Örgüt Kuramı Meydan Okumalar ve Bakış Açıları. (Çev.: F. Man, ve Ş. A. Turan) Ankara: Nobel Akademik Yayıncılık.

Porter, M., ve Kramer, M. (2011). Creating Shared Value. Harvard Business Review, 89(1/2), 62-77.

Prasad, A., ve Mills, A. J. (2010). Critical Management Studies and Business Ethics: A Synthesis and Three Research Trajectories for the Coming Decade. Journal of Business Ethics, 94, 227-237.

Racelis, A. D. (2013). Developing A Virtue Ethics Scale: Exploratory Survey of Philippine Managers. Aliza D. Racelis, Developing A Virtue Ethics Scale: Exploratory SuAsian Journal of Business and Accounting, 6(1), 15-37.

Seneca. (2015). Hoşgörü ve Ruh Dinginliği Üzerine. Ankara: Doğubatı Yayınları.

Sevim, S., ve Şener, E. (2019). A Concept Analysis At Organizational Level: Baby Friendly Hospital. 4. International Health Sciences and Management Conference. İstanbul.

Sparc Advocacy Trainings Begin In Nigeria Today (2020). Erişim Adresi: https://www.vitalvoices.org/2013/08/ 
Şener, E. (2018). Örgütsel Teoriden Örgütsel Davranışa Erdem. Ankara: Savaş Yayınları.

Tsoukas, H., ve Chia, R. (2013). Felsefe ve Örgüt Teorisi. Ankara: Nobel Yay.

Yıldırım, E. (2010). Örgüt Kuramlarında Yeni Gelişmeler: Postmodern ve Eleştirel Bakış. (Edit.: S. Sargut ve Ş. Özen, Örgüt Kuramları). Ankara: İmge Kitabevi.

Youtube.com. (2020). What's it like to work at Google? Erişim Adresi: https://www.youtube.com/ 